\title{
CONTORNOS FORMATIVOS EM TEMPOS DE PANDEMIA: PERCEPÇÕES DE PROFESSORAS/PESQUISADORAS DA EDUCAÇÃO BÁSICA
}

\section{Formative Contours in Pandemic Times: Perceptions of Teachers/Researchers from the Basic Education}

\author{
Nathália Cristina Amorim Tamaio de Souza ${ }^{1}$ \\ Flávia Graziela Moreira Passalacqua ${ }^{2}$ \\ Rayana Silveira Souza Longhin Lourenço ${ }^{3}$ \\ Evelin Oliveira de Rezende Piza ${ }^{4}$
}

\begin{abstract}
Resumo: $O$ presente momento, impactado pela passagem de uma pandemia, provocou mudanças nas práticas de professores que atuam em diferentes etapas da educação e na formação docente. Pensando nesse cenário, neste artigo conduzimos uma discussão acerca dos aparentes delineamentos formativos que vêm sendo assumidos no período de ensino remoto, com o objetivo de identificar e analisar suas implicações para as práticas pedagógicas, tomando como fonte geradora de dados nossas próprias experiências, enquanto professoras e pesquisadoras da Educação Básica. A pesquisa empreendida é qualitativa e aprecia os dados suscitados à luz da Análise de Conteúdo e do referencial nacional e estrangeiro do campo da formação continuada de professores. Sinaliza que os recentes contornos esboçados para a formação de professores promovem o fortalecimento da relação entre pares, o engajamento para a aprendizagem de estratégias de ensino condizentes com as demandas da educação não presencial, e o apoio da equipe gestora.
\end{abstract}

Palavras-chave: Formação docente. Educação Básica. Pandemia Covid-19.

Abstract: The present moment, impacted by the passing of a pandemic, caused changes in the practices of teachers who work in different stages of education and teacher training. Thinking about this scenario in this paper we conduct a discussion about the apparent formative designs that have been assumed in the period of remote teaching, with the objective of identifying and analyzing its implications for pedagogical practices, taking as source of data our own experiences, as teachers and researchers of Basic Education. The research undertaken is qualitative and appreciates the data raised in the light of Content Analysis and the national and

\footnotetext{
1 Doutoranda em Educação na Universidade Estadual de Campinas (UNICAMP) e professora do Ensino Fundamental I no Serviço Social da Indústria (SESI) de Araraquara, SP. Orcid: http://orcid.org/0000-0001-62801784. E-mail: nathytamaio@ hotmail.com.

2 Doutora em Educação pela Universidade Estadual Paulista (UNESP) e pós doutoranda na mesma universidade, campus de Araraquara, SP. Orcid: https://orcid.org/0000-0001-6619-3069. E-mail: flaviagraziela@hotmail.com.

3 Doutora em Educação pela Universidade Estadual Paulista (UNESP) e professora de Ensino Fundamental na rede pública municipal de Ibaté, SP. Orcid: https://orcid.org/0000-0002-7384-1543. E-mail: E-mail: rayanaalonghin@gmail.com.

${ }^{4}$ Doutoranda em Educação na Universidade Estadual Paulista (UNESP) e professora de Educação Infantil na rede pública municipal de Araraquara, SP. E-mail: evelinrezende.uab@gmail.com. Orcid: https://orcid.org/0000-00025739-347X.
} 
foreign referential in the field of continuing teacher education. It signals that the recent outlines for teacher training promote the approximation of the relationship between peers, the engagement for the learning of teaching strategies consistent with the demands of nonclassroom education, and the support of the management team.

Keywords: Teacher training. Basic Education. Covid-19 pandemic.

\section{Introdução}

A formação e o trabalho dos professores jamais serão os mesmos. Se tivéssemos que compilar o estudo ora apresentado em uma única frase, seguramente, seria esta.

Ao longo de seu percurso histórico, a formação docente sofreu inúmeras mudanças conceituais e na forma de operacionalização de sua função central, qual seja: o aprimoramento profissional de professores. Atravessamos períodos distintos ${ }^{5}$ até que pudéssemos chegar ao consenso de que a formação deveria ser permanente e alterar-se de acordo com as necessidades docentes, conforme enfatizam Passalacqua et al. (2019).

Durante muito tempo, a formação inicial foi considerada suficiente para a preparação do professor. Entretanto, nas últimas décadas, o seu inter-relacionamento com o desenvolvimento profissional suscitou a importância de atualização e constante aperfeiçoamento dos educadores. Segundo Nóvoa (1995), a necessidade de continuidade de quem já é professor (formação continuada) é criada a partir da evolução do conhecimento, quanto aos processos de ensinar e aprender, das reformas empreendidas nos currículos. Desde meados de 1980, as mudanças no processo de compreender e gerir a formação docente mostraram-se mais expressivas, pois os professores passaram a tentar se colocar no centro dos debates e das problemáticas de investigação em torno da educação.

Autores como Hargreaves (1998), Marcelo García (1999), Nóvoa (1991), e, mais recentemente, Imbernón $(2016 ; 2010)$, defendem que mudanças são necessárias para a oxigenação da prática docente e a revitalização da educação como um todo, na perspectiva de busca pela qualidade do ensino. No entanto, quando pensamos em mudanças, remetemo-nos a algo que se constrói durante algum tempo, que perpassa discussões prévias, estudos, experimentações, critérios de viabilidade, tempo para adaptações; e não a uma situação imediata, abrupta, sem precedentes. Até que nos deparamos com uma pandemia mundial.

A pandemia acarretada pelo surto do novo Coronavírus (SARS-CoV-2), causador da COVID-19, trouxe consigo uma série de impactos em diferentes dimensões da tessitura social nos mais variados contextos do globo (FREITAS; NAPIMOGA; DONALISIO, 2020). Evidentemente, a educação não ficou imune a tais impactos, já que a escola é, por si só, um local de aglomeração de pessoas. Esta tornou-se, inclusive, uma das primeiras instituições a sentir os efeitos de transformações que, decididamente, deixarão marcas perenes.

A celeridade com que mudanças vêm acontecendo nesse momento de pandemia é um fato excepcional e que mobilizou a reinvenção dos modos de gerir conteúdos, ministrar aulas, planejar, avaliar, e até mesmo de se comunicar. Repentinamente, professores dos diferentes níveis de ensino precisaram se ajustar a um cenário que sequer havia sido conjecturado.

Com o fechamento das escolas, nós, professoras e professores da Educação Básica, tivemos que repensar radicalmente as práticas pedagógicas que aprendemos a dominar ao longo

\footnotetext{
5 O parecer CNE/CP n ${ }^{\circ}$ 02/2015, deliberado pelo Ministério da Educação e pelo Conselho Nacional de Educação (Brasil, 2019), em sua versão atualizada sintetiza o histórico dos movimentos da formação docente no Brasil.
} 
do processo formativo e da carreira docente. O desafio foi criar um modelo de aulas remotas que abarcasse os recursos digitais disponíveis nas instituições de ensino e nas residências dos estudantes, enquanto os prédios escolares permanecem fechados. Encará-lo, demandou, sobretudo nos primeiros meses, o acionamento de reservas de equilíbrio emocional para modificarmos práticas pedagógicas, às quais estávamos ajustados, e nos sentirmos à vontade com o que ainda não sabemos ou não dominamos, nos adaptando a um novo normal didático.

Nesse cenário, instalou-se, na educação, o que conhecemos como ensino remoto. Segundo Moreira e Schlemmer (2020, p. 9), no ensino remoto:

[...] o ensino presencial físico (mesmos cursos, currículo, metodologias e práticas pedagógicas) é transposto para os meios digitais, em rede. O processo é centrado no conteúdo, que é ministrado pelo mesmo professor da aula presencial física. Embora haja um distanciamento geográfico, privilegia-se o compartilhamento de um mesmo tempo, ou seja, a aula ocorre num tempo síncrono, seguindo princípios do ensino presencial. A comunicação é predominantemente bidirecional, do tipo um para muitos, no qual o professor protagoniza vídeo-aula ou realiza uma aula expositiva por meio de sistemas de webconferência. Dessa forma, a presença física do professor e do aluno no espaço da sala de aula geográfica são substituídas por uma presença digital numa sala de aula digital. No ensino remoto ou aula remota o foco está nas informações e nas formas de transmissão dessas informações.

A utilização das tecnologias digitais em rede na Educação Básica nos mostra que os ambientes virtuais modificam o domínio sobre o fazer docente praticado na modalidade presencial, pois são outros espaços e tempos pedagógicos que se apresentam.

No entanto, faz-se imperioso que não percamos de vista o princípio de que a formação de professores é antes uma práxis que uma teoria sobre uma prática. Esse olhar provocativo sobre a formação de professores necessita voltar-se para o entendimento de que a docência pode se desenvolver de diferentes formas e em cada uma delas a condição de possibilidade para a aprendizagem é a criação de estratégias pertinentes a cada situação. Isso requer entender que a docência e a aprendizagem são processos complexos. Nessa condição, somos compelidos a uma mobilização em direção ao novo. Mas que novo? Para qual contexto? Se os processos educativos já estavam sendo questionados pelos desafios impostos pela contemporaneidade, com a pandemia da Covid-19 se intensificaram e adquiriram as 'formas' da imprevisibilidade e da incerteza. O novo, então, é o agora que precisa ser (re)pensado e (re)construído. Assim, inovar, inventar, criar, transformar constituem as palavras de ordem do atual momento. Pensar e problematizar a inovação são, portanto, imperativos nas formas de ensinar e aprender na contemporaneidade (CARVALHO; ARAÚJO, 2020).

Paradoxalmente, instruir os alunos a utilizarem ferramentas digitais - que nós mesmos pouco utilizamos - e ainda manter o equilíbrio mental de uma turma - quiçá duas ou mais diante da ameaça do desconhecido, tornou-se muito mais difícil do que alfabetizá-los e ensinálos conteúdos curriculares remotamente. Do mesmo modo, preparar-nos para essa complexa tarefa mobilizou esforços formativos muito mais vigorosos, advindos tanto das instituições, em nome de suas equipes gestoras, como do próprio corpo docente entre si.

Isso posto, e considerando nossas experiências como potenciais fontes geradoras de dados sobre o tema, objetivamos, no presente artigo, identificar e analisar os novos contornos formativos que têm sido assumidos na Educação Básica e suas implicações para as práticas pedagógicas. Para tanto, realizamos uma pesquisa qualitativa de natureza descritivo-analítica e 
recorremos ao referencial teórico que congrega obras sobre a formação continuada de professores, sendo ele constituído por autores estrangeiros e brasileiros.

Antecipamos que a resposta ao objetivo delineado revelou indícios de uma postura mais ativa por parte dos professores, além do estreitamento das relações entre pares e a equipe gestora. Contendo-nos para não revelar em demasia o que está por vir, passamos a expor a sequência estrutural do artigo: na próxima seção, descrevemos nossas experiências sobre a formação docente em nossos contextos de trabalho; na seguinte, apresentamos a opção metodológica que subsidia o artigo; posteriormente, expomos a seção de análise dos dados; e, nas considerações finais, tecemos uma breve síntese sobre o problema investigado.

\section{Contornos formativos inacabados e inapagáveis}

Como mencionado anteriormente, a pandemia em curso da COVID-19 tem gerado inúmeras alterações na vida cotidiana, mudanças inimagináveis até o momento. Tivemos que nos isolar por completo, ver nossos planos sendo adiados, além de presenciar o sofrimento e as perdas de muitos ao redor de todo o mundo. Esse cenário trouxe, como era de se esperar, desafios a todos os setores da sociedade, através de mudanças econômicas, políticas e sociais.

$\mathrm{Na}$ escola, a nova realidade culminou em transformações na prática docente e nos processos de ensino e aprendizagem, exigindo dos professores a utilização de tecnologias para o alinhamento à modalidade de ensino remoto. Sobre o uso de recursos tecnológicos, Araújo (2012, p. 15) observa que:

[...] embora já se façam presentes em salas de aula, ainda não possuem a centralidade do velho quadro-negro - ou verde ou azul, contrastado pelos gizes coloridos ou não, ou branco, contrastado pela escrita por meio do marcador para quadro-branco (conhecido popularmente como pincel anatômico), colorido ou não -, nem com ele repartem a solidão de que ainda desfruta, no interior das salas de aula, diante da afirmação das novas tecnologias educativas.

Assim, ainda que as tecnologias não estejam alheias à educação - o quadro branco, o pincel anatômico e a lousa digital são exemplos de inserção da tecnologia na sala de aula -, assumi-las como principal estratégia de mediação do ensino é algo novo e que, por essa razão, requer diferentes contornos para a formação de professores. Pensando nisso, nesta seção descrevemos três relatos oriundos de nossas próprias experiências - por esta razão, escritos na primeira pessoa do singular - enquanto docentes da Educação Básica, para, num segundo momento, realizarmos discussões e análises acerca do exposto.

Cumpre observar que a escolha pelos nossos próprios relatos como fonte de dados tem inspiração nas possibilidades metodológicas da autoetnografia, uma abordagem de pesquisa qualitativa. Reed Danahay (1997) ressalta que a produção autoetnográfica envolve uma relação entre self, compreendido como as experiências do sujeito, e sociedade, e a define como uma forma de autonarrativa que coloca o self dentro de um contexto social.

\section{1 Mudanças formativas pelas lentes de uma professora alfabetizadora}

Na condição de professora da Educação Básica, atuante no primeiro ano do Ensino Fundamental, bem como de pesquisadora que investiga a formação de professores alfabetizadores, passo a relatar minha própria experiência - consubstanciada, também, pela 
experiência de meus pares de trabalho - sobre os novos contornos da formação de professores e seus efeitos no trabalho docente até o presente momento.

Primeiramente, cumpre informar que trabalho em uma escola pertencente a uma das maiores redes de ensino particular do estado de São Paulo e, por essa razão, vejo-me imersa em uma realidade, de certo modo, privilegiada. No intervalo entre os meses de abril e maio, a rede em questão idealizou e lançou uma plataforma online com capacidade para comportar os mais de noventa e cinco mil estudantes distribuídos em escolas por todo o estado, além de Guias ${ }^{6}$ para os estudantes, as famílias e os professores, com diretrizes bastante objetivas. A partir de então, as aulas passaram a ocorrer remotamente, contando com momentos síncronos e assíncronos.

Para atender ao novo formato de mediação da aprendizagem, nós, professores, fomos submetidos a uma série de treinamentos online, oferecidos pela unidade sede, que deram suporte à utilização dos meios tecnológicos. Esse processo se deu de forma aligeirada, visto que a retomada das atividades escolares foi iniciada poucos dias depois. Concomitantemente, foram conduzidas reuniões de Discussão Pedagógica Coletiva (DPC) com a gestão local.

Os diálogos, estudos e encaminhamentos engendrados nas DPCs semanais passaram a constituir o principal espaçotempo de formação docente, representando não apenas o momento de escuta, como também - e principalmente - o lugar de fala dos professores. As instruções e outras propostas que nem sempre correspondiam aos reais anseios da equipe como um todo, outrora realizados, cederam lugar a partilhas de experiências bem-sucedidas, trocas de atividades e exposição de dificuldades. Em ocasião alguma se deu tanta voz aos professores.

Ainda que as defasagens em relação ao ensino sejam inevitáveis, uma vez que não conseguimos atingir a totalidade dos estudantes de forma não presencial, faz-se importante salientar os saltos qualitativos da formação docente. Talvez devido às exigências serem ainda mais acentuadas e, certamente, em virtude da imperiosidade de os professores se ajudarem mutuamente, os canais de comunicação alternativa, isto é, não institucional (como o aplicativo WhatsApp), também têm sido utilizados como dispositivos formativos, servindo como apoio extra para orientações e trocas produtivas. Assim, foi possível apurar a aproximação entre os professores em busca de objetivos comuns e o inegável apoio da equipe gestora, responsável por nos oportunizar a participação efetiva na seleção de temas a serem discutidos e nos munir de orientações pontuais e imprescindíveis para atuarmos com mais segurança nesse momento em que tantas incertezas se instauram.

Como pedagoga, incorporei ao trabalho em alfabetização o conjunto de ideias e possibilidades partilhadas por professoras especialistas. Inclusive, realizamos uma série de aulas síncronas conjuntas, promovendo a discussão de determinados temas sob o enfoque interdisciplinar. Vale salientar que a interdisciplinaridade mobiliza o aluno a fazer conexões no currículo. Há menos exercícios só para praticar o que se aprendeu, e mais exercícios para aplicar o que se aprendeu em novos contextos (KLEIMAN, 2001)

Práticas dessa natureza não haviam sido oportunizadas anteriormente devido à escassez de tempo para planejamento coletivo; raramente tínhamos momentos para fazer trocas tão significativas, para pensar em adaptações, para conversar sobre as necessidades mais urgentes de cada turma e, a partir disso, remodelarmos nossa prática pedagógica. Nesse sentido, espero

\footnotetext{
6 Esses guias são materiais elaborados pela Rede Sesi para orientação de professores, alunos e famílias. Contemplam desde instruções voltadas ao acesso à plataforma de estudos (Conexão Digital) até questões socioemocionais (encorajamento, motivação, colaboração) para o enfrentamento do período de ensino remoto.
} 
que o novo delineamento formativo que nos foi oferecido não se perca, pois suas potencialidades deixarão marcas que não podemos e nem queremos apagar.

\subsection{Diferentes possibilidades formativas, na ótica de uma professora do Ensino Fundamental}

Sou professora do $4^{\circ}$ ano em uma escola municipal do interior paulista, e nessa experiência atípica de docência em tempos de Pandemia, a principal reflexão que trago é a percepção do quanto os professores estão se ajudando nessa caminhada.

Num primeiro momento, foi possível notar nas reuniões ocorridas na Hora de Trabalho Pedagógico Coletivo (HTPC), o desalento que tomou conta das conversas entre os professores, potencializado pelo medo do desconhecido e a ausência de um encaminhamento concreto para os novos rumos da docência. Passado esse receio inicial, senti uma onda de empatia e generosidade se instalando, em que os professores se colocaram, verdadeiramente, no lugar de alunos e tiveram que aprender novas possibilidades para ensinar, despindo-se de resistências e posturas de individualismo - bastante comuns à profissão docente - e aprendendo com os dilemas e entraves que passaram a integrar o trabalho educativo.

Felizmente, tenho a oportunidade de observar, diariamente, através do grupo de WhatsApp ${ }^{7}$ criado com a finalidade formativa, o quanto os professores, entre os quais me incluo, e a equipe gestora têm se amparado e trocado orientações, dicas e reflexões; o quanto se reinventaram frente aos novos desafios e não deixaram de se autoavaliar e melhorar, em uma busca ininterrupta por oferecer situações promotoras de um ensino significativo e transformador para nossos alunos.

Nesse movimento, intensificou-se um trabalho colaborativo entre os pares, no sentido de que se buscou uma legítima transformação da prática educacional, valorizando-se, assim, o trabalho em equipe e o exercício coletivo e reflexivo da profissão.

Concebo que, para que esses processos formativos possam adquirir como eixo de referência o desenvolvimento profissional docente, sua proposta teve que ser desenvolvida $n a$ e a partir da escola, abarcando elementos fundamentais na construção de uma perspectiva educativa que considere o papel central dos contextos nos quais a atividade docente é realizada, especialmente na situação atual de uma sociedade em permanente mudança. Nesse sentido, endosso a posição de Nóvoa (2001, p .25), ao postular que:

É no espaço concreto de cada escola, em torno de problemas pedagógicos ou educativos reais, que se desenvolve a verdadeira formação. Universidades e especialistas externos são importantes no plano teórico e metodológico. Mas todo esse conhecimento só terá eficácia se o professor conseguir inseri-lo em sua dinâmica pessoal e articulá-lo com seu processo de desenvolvimento.

O autor chama a atenção para o fato de que é dentro da escola e da profissão, ou seja, no ensino e no trabalho docente, que se deve buscar uma transformação para as práticas de formação de professores, devido, principalmente, à gama das necessidades formativas e dos desafios postos pelo cenário contemporâneo. E é exatamente essa perspectiva que vem sendo

7 WhatsApp é um aplicativo multiplataforma de mensagens instantâneas e chamadas de voz para smartphones. Além de mensagens de texto, os usuários podem enviar imagens, vídeos e documentos em PDF, além de fazer ligações grátis por meio de uma conexão com a internet. 
observada nas discussões que participo, nas quais os professores têm assumido o tão buscado papel de protagonistas da educação.

Em linhas gerais, considero que ainda precisamos trilhar uma caminhada considerável no sentido de implementar todos os ajustes necessários às práticas docentes na atualidade em busca de formas mais efetivas para ensinar e, assim, minimizar as inúmeras dificuldades que vêm atingindo, inesperada e profundamente, alunos e professores. Contudo, acredito que o novo cenário nos trouxe a convicção da importância que nós, professores e professoras, tão desvalorizados pelo sistema, temos para a sociedade.

\subsection{Contexto pandêmico e formação entre pares, por uma professora da Educação Infantil}

Em meio ao caos da pandemia, muito se tem ponderado sobre os modos de ensinar crianças pequenas, de 3 a 4 anos de idade, por meio da ferramenta tecnológica WhatsApp, a qual tem sido instrumento fundamental para os recentes delineamentos da educação e as consequentes mudanças no ensino.

No contexto educativo em que estou inserida, pude acompanhar o processo de deslocamento do lócus de ensino, antes fixado em meio aos muros escolares, para a residência dos alunos. Essa ruptura representou um choque para a categoria docente que, 'da noite para o dia', precisou pensar em estratégias de reconfiguração e oferta do ensino. Diante dessa nova realidade regida pelo início da extensão da escola no interior das vivências familiares, comecei a refletir sobre os próximos passos que daríamos: que caminhos seguiremos? Será que aprenderemos a trabalhar de modo não presencial, considerando que alguns professores, sobretudo os que já têm idade avançada, sequer conhecem funções básicas de um computador ou de um dispositivo móvel?

Assim, atentei-me às ações de auxílio e acolhimento dos meus pares de profissão, que dividiram comigo suas angústias e preocupações, revelando inseguranças frente ao contexto de isolamento social, às novas maneiras de conviverem com seus familiares e amigos, à reclusão do e no espaço público e, principalmente, à reconfiguração do trabalho com o ensino remoto. Antes de qualquer coisa, buscamos nos confortar e compreender as especificidades desse cenário pandêmico. O papel da Coordenação Pedagógica, que se dispôs a nos orientar sobre o modo mais 'adequado' de transformarmos as aulas presenciais em aulas virtuais, também foi importante.

O principal desafio, no entanto, foi tentar ensinar por meio do celular, a partir de mensagens, áudios, vídeos postados em grupos de WhatsApp, contando com a mediação de um responsável pela criança. Como saberíamos se a criança estaria, de fato, recebendo os materiais, assistindo aos vídeos? Como iríamos apurar a apropriação do ensino? As aprendizagens seriam efetivas? Hoje, percebo que responder a todas estas questões e ter garantias da efetividade do trabalho realizado é algo que vai além do que nos cabe. No entanto, a experiência nos fez refletir sobre a importância de podermos contar uns com os outros para atravessarmos barreiras que, por um instante, pareciam impenetráveis.

Nessa conjectura, me autodesignei a tarefa de estender os braços e a escuta para esses professores, a fim de que, juntos, reiniciássemos o processo de pertencimento da classe docente, que por muitos anos permaneceu fria e distante. Percebi, por meio dessas ações de acolhimento, o renascimento do sentido de unidade entre os pares, e isso tem fortalecido o estreitamento dos laços entre os membros da equipe. 


\section{Percurso metodológico}

Conforme explicitado na Introdução, realizamos um estudo qualitativo de natureza autoetnográfica, partindo de nossos relatos enquanto professoras da Educação Básica, por considerarmos que as experiências de cada uma de nós seriam uma potente fonte de dados que, além de configurar o corpus da pesquisa, iluminaria o constante repensar de nossas práticas pedagógicas.

A autoetnografia é um método de pesquisa que se caracteriza por usar a experiência pessoal do pesquisador para descrever crenças, práticas e experiências culturais; valorizar os relacionamentos do pesquisador com os outros; usar a autorreflexão para nomear e questionar as intersecções entre o eu e a sociedade, o particular e o geral, o pessoal e o político; relatar o processo de descoberta do que fazer, de como viver e do significado das lutas das pessoas; equilibrar rigor, emoção e criatividade intelectuais e metodológicos em estilo literário (ADAMS et al, 2015). Assim sendo, os procedimentos de autoetnografia requerem reconhecer que "somos parte daquilo que estudamos" e "mais honestos enquanto pesquisadores, quando reconhecemos que nossas vidas pessoais e emoções estão entrelaçadas de inúmeras formas a quem, o que e como estudamos" (ADAMS et al., 2015, p. 15). Desse modo, é preciso enfatizar que não é nossa intenção apresentar generalizações, mas apontar possibilidades de reflexão sobre o tema abordado neste artigo a partir de uma perspectiva que parte de nossas vivências pessoais e se inserem em um dado contexto.

Pensando na organização das percepções relatadas, acolhemos como técnica de análise a Análise de Conteúdo, segundo as diretrizes de Bardin (2011). Inicialmente, estruturamos a fase que a autora denomina como pré-análise, ou seja, a organização do material selecionado. Na pré-análise efetuada foram consideradas diferentes operações, as quais contemplaram: o recorte metodológico baseado em critérios bem definidos do material de análise; a pertinência, caracterizada pela escolha da fonte de informações que corresponde ao objetivo da análise; e a sistematização, que consistiu na disposição metódica do material analisado. A segunda fase referiu-se ao momento de exploração do material, a qual incidiu em operações de codificação. Pode-se inferir que, no caso deste estudo, essa fase corresponde ao cotejamento entre os relatos e a literatura da área.

Ao realizarmos o tratamento dos dados emergentes de nossas escritas, deparamo-nos com aspectos que se sobressaíram e esses passaram a constituir três eixos de análise: I Fortalecimento da relação entre pares; II - Apoio da gestão escolar; e III - Protagonismo docente. A descrição dos relatos trouxe à tona algumas questões bastante comuns ao campo da formação continuada de professores. Em todas elas são aludidos temas que envolvem a valorização do processo permanente de formação docente (IMBERNÓN, 2016; 2010) e a importância de os professores se auxiliarem em tempos de mudanças (HARGREAVES, 2002; 1998). Na seção a seguir analisamos as especificidades de cada eixo elencado.

\section{0 que nos contam os recentes contornos formativos?}

Os aspectos desencadeados pelos relatos nos trazem perspectivas já exploradas pelo campo da formação de professores e consideradas determinantes para a realização de práticas bem-sucedidas. No entanto, se nos determos aos estudos da área, tais como o mapeamento realizado por Gatti e Barretto (2009) e por Gatti, Barretto e André (2011), visualizaremos um cenário de recorrentes falhas quanto ao protagonismo docente e questões relacionadas ao apoio da gestão escolar e ao fortalecimento da relação entre pares. O que parece ter mudado no contexto atual é, portanto, um marco significativo para a formação de professores, visto que em 
decorrência da atual situação emergencial, a principal mobilização tem partido dos próprios professores e equipes gestoras locais.

Com as inúmeras demandas que vêm sendo modificadas diariamente, o protagonismo docente tornou-se mais ostensível na medida em que os professores assumiram o papel de principais responsáveis por seu desenvolvimento profissional, reconhecendo os saberes e as necessidades inerentes à sua prática, percurso e identidade. Eles passaram a agenciar o seu contexto de trabalho, refletindo sobre os modos de sua atuação prática, afastando-se criticamente da estrutura burocrática e cristalizada da profissão e ampliando a sua visão de ensino para além da sala de aula tradicional/presencial e passando a habitar o universo digital e tecnológico (CONTRERAS, 2002).

A esse respeito, Imbernón (2016) ressalta que para uma comunidade de práticas formativas ser constituída, deve-se apostar em uma transformação nas relações de poder no interior das instituições e na urgência de os docentes assumirem seu protagonismo através de reflexões, discussões e compartilhamentos dos processos educacionais selecionados na esfera prática da profissão. Desse modo, o que os relatos descritos neste artigo testemunham quanto à ampliação da participação docente na busca de resoluções de problemas que assolam seus fazeres cotidianos em tempos de pandemia, podem ser traduzidos como uma autêntica postura de encorajamento e autonomia que, certamente, permanecerá para além do momento vivenciado atualmente.

Importante destacar que a assunção de práticas autônomas não representa, em hipótese alguma, o suprimento de ações colaborativas e o individualismo docente. Pelo contrário. $\mathrm{O}$ protagonismo e a autonomia docentes residem em aspectos pessoais - que abrangem $o$ compromisso ético e moral - e sociais - que abarcam os relacionamentos entre os pares de profissão e os valores que os norteiam - incidindo em uma ação humanista e não meramente técnica, um componente educativo superior ao trabalhista, um atributo circunstancial de situações e métodos, sendo mais do que um predicado particular ou psicológico (CONTRERAS, 2002).

Conforme apregoado nos relatos narrados, ao se colocarem como protagonistas, os professores incumbem a si mesmos a tarefa de se unirem. A união dos pares possibilita a reflexão e a aprendizagem mútua através das trocas de conhecimentos e experiências, construindo coletivamente um projeto educacional no qual prevaleça uma formação baseada na cooperação e na solidariedade.

Gatti, Barretto, André e Almeida (2019) reforçam o exposto ao explanarem que os professores se reúnem com o desígnio de alcançar novas informações, ressignificar crenças e conhecimentos precedentes e edificar novas ideias e experiências, visando trabalhar com o escopo específico de aperfeiçoar a prática e a aprendizagem dos alunos. Segundo as autoras,

[...] o professor aprende e se desenvolve dentro de um contexto mais abrangente, ou seja, comunidade, instituição, organização política e profissão. Esses espaços criam oportunidades para que professores pensem, falem, leiam e escrevam sobre seus trabalhos diários, incluindo seus contextos sociais, culturais e políticos mais abrangentes, de maneira intencional e planejada. Professores que aprendem a refletir junto com seus pares colaboram reciprocamente para o desenvolvimento profissional de cada um e enriquecem-se mutuamente (GATTI et al., 2019, p. 189-190). 
Embora o eixo sobre o protagonismo docente tenha sido representado de modo equivalente nos relatos, é preciso salientar a discrepância observada quanto ao eixo sobre o fortalecimento das relações entre pares, o qual se destacou no terceiro relato.

$\mathrm{O}$ aumento exponencial e qualitativo das relações entre docentes descrito no relato da professora de Educação Infantil pode ser justificado pela alteração no comportamento pedagógico que o momento de pandemia passou a exigir. Como, nesse caso, os colegas de trabalho mencionados têm idade mais avançada, pode-se inferir, com base no ciclo de vida profissional dos professores, apresentado por Huberman (1992), que estes permaneciam na fase de distanciamento afetivo e de conservantismo ${ }^{8}$. Com a chegada da pandemia, no entanto, as práticas pedagógicas pertencentes ao repertório de ações docentes desses professores foram submetidas a uma drástica mudança que implicou a procura pelos pares mais jovens e, portanto, mais próximos à realidade virtual, atualmente em voga no campo educativo. A declaração "me autodesignei a tarefa de estender os braços e a escuta para esses professores, a fim de que, juntos, reiniciássemos o processo de pertencimento da classe docente, que por muitos anos permaneceu fria e distante" corrobora o apontamento depreendido.

O aquecimento dos vínculos foi algo que também contagiou a relação entre professores e equipes gestoras. Nesse eixo, porém, as nuanças identificadas nos relatos foram mais acentuadas, já que representaram alta frequência no primeiro relato, média no segundo e baixa no terceiro. Uma vez que a frequência é substancialmente superior na escola de rede particular, colocamo-nos a refletir sobre a autonomia e o papel da gestão escolar em instituições públicas e privadas.

$\mathrm{Na}$ análise que aqui tecemos, consideramos que as ações de apoio aos docentes oriundas da equipe gestora faz-se mais aparente na escola particular porque o plano de organização de ensino remoto elaborado pela rede que dirige as normas adotadas pela instituição foi contundente e objetivo, mostrando alternativas que deram um suporte efetivo aos profissionais das escolas. Nesse prisma, por mais que os professores tenham assumido uma postura de protagonismo e elevado sua autonomia no curso desse novo contorno formativo que vem se constituindo, a gestão escolar local pôde contribuir fortemente por estar devidamente munida de orientações advindas de instâncias superiores.

Em contrapartida, os relatos 2 e 3, ao atribuírem a gradativa superação do caos instalado pela pandemia no âmbito da docência às trocas mútuas entre os próprios professores, mencionando o apoio da gestão de modo menos enfático, admitiram, nas entrelinhas de suas declarações, que as orientações formativas do sistema público foram incipientes. Tal constatação, ainda que abarque realidades específicas, é ratificada no levantamento promovido pela revista Nova Escola.

A pesquisa, intitulada A situação dos professores no Brasil durante a pandemia (SEMIS, 2020), coletou respostas de mais de 9,5 mil profissionais, entre os dias 16 e 28 de maio, por meio de questionário online. Docentes da rede pública representaram cerca de $75 \%$ dos respondentes. Dentre as dimensões investigadas, destacamos a formação/preparação para o uso de tecnologias e enfrentamento da situação pandêmica, a qual indicou que mais de $50 \%$ dos professores não receberam orientações formativas. Esse dado reitera nossa verificação acerca da ausência de amparo formativo aos professores, especialmente na esfera da educação pública,

\footnotetext{
8 Os docentes que se encontram nesta fase queixam-se do ânimo dos professores mais novos. Uma de suas principais consequências é o isolamento profissional (Huberman, 1992).
} 
e está em conformidade com as ponderações de Falsarella (2018) que, em pesquisa ${ }^{9}$ realizada sobre a formação continuada em serviço oferecida por equipes gestoras de escolas municipais no interior paulista, revela o descompasso, há tempos firmado, entre as ações priorizadas nos momentos de reuniões pedagógicas e os reais anseios formativos dos professores.

Autores como Nóvoa (2001) e Imbernón (2016) alertam para a importância de a formação continuada estar voltada aos interesses do corpo docente e às suas carências pessoais/ profissionais. Destarte, salientamos que o apoio da gestão escolar é altamente relevante para que os professores se sintam seguros para lecionar.

De acordo com Gimeno Sacristán (2000), a formação de professores, metodologicamente falando, é tão complexa como a dos próprios alunos e demanda ações que não se restrinjam ao 'o que fazer' e 'como fazer'. É preciso, especialmente nesse momento de pandemia, que seja instalada uma atmosfera formativo-colaborativa que considere, também, a afetividade, a empatia, a importância das trocas e do compartilhamento de ideias e a valorização de boas práticas, pois, segundo o referido autor, os professores costumam agir de acordo com suas convicções ou mecanismos adquiridos por meio da socialização em seu contexto de ação.

Passalacqua et al. (2019) enfatizam que os professores sentem a necessidade de serem valorizados. Na visão dos autores, essa valorização envolve "motivação, apreço e enaltecimento do trabalho desenvolvido pelos profissionais, a fim de que estes se sintam realmente envolvidos nas atividades propostas em contexto de formação continuada" (p. 246). Tais aspectos se encontravam subestimados, até que a pandemia em curso despertasse nas escolas, nas famílias e na sociedade como um todo, a compreensão da indiscutível importância da categoria docente.

De modo geral, compreendemos que os três eixos analisados neste artigo detém fortes influências nos recentes contornos formativos que vêm sendo delineados. Contornos estes que estão inacabados, uma vez que muitos caminhos podem ser alterados, e, ao mesmo tempo, que são inapagáveis, visto que as transformações ocorridas na formação docente, especialmente no que se refere ao novo formato de relação entre pares e às consequentes mudanças nas práticas pedagógicas, indubitavelmente, deixarão marcas vívidas, mesmo quando a crise pandêmica cessar.

\section{Considerações finais}

Neste artigo, buscamos identificar a analisar quais são os recentes contornos da formação de professores da Educação Básica no contexto pandêmico, bem como as possíveis implicações as práticas pedagógicas, considerando como delimitação os contextos de ensino em que nós, professoras pesquisadoras e autoras deste texto, encontramo-nos imersas. Ao analisarmos as narrativas descritas a partir de nossas próprias vivências enquanto professoras, detectamos alguns fatores que se apresentaram de modo recorrente: o protagonismo docente, o fortalecimento das relações entre pares e o apoio da gestão escolar. Estes demonstraram pontos positivos em relação às mudanças formativas ocasionadas pelo conflito da pandemia.

Destacamos as gradações entre os eixos de análise elencados, considerando as diferentes realidades educacionais descritas, especialmente em relação ao pertencimento à rede pública ou privada e ao perfil do professorado. Embora as diferenças não possam ser desconsideradas, elas não incidiram em contraposições.

\footnotetext{
${ }^{9}$ Sublinhamos que a pesquisa em referência contempla a região na qual as escolas de atuação das autoras do presente artigo / professoras de Educação Básica estão situadas.
} 
Uma vez cotejados, pôde-se averiguar aderência entre os dados suscitados e o que reconhecidos autores concebem como caminhos promissores para a formação docente, haja vista que os estudos destacam a importância de os momentos formativos despontarem dos problemas enfrentados pelos professores e se desenrolarem a partir da própria relação profissional entre eles (HARGREAVES, 2002; IMBERNÓN, 2016; NÓVOA, 2001).

Por fim, e respondendo ao nosso objetivo central, a pesquisa indicou que mesmo o atual panorama educacional tendo provocado inúmeras perdas, sobretudo em termos de efetividade da aprendizagem dos alunos; e mesmo os professores tendo sofrido com as repentinas mudanças às quais foram e continuam sendo submetidos, a formação docente jamais será a mesma. $\mathrm{E}$ atribuímos a essa afirmação um tom positivo, pois junto ao sofrimento que nos deixou completamente desolados no início, aconchegaram-se o amadurecimento, a resiliência, o acolhimento, as mudanças de olhares, o efetivo trabalho conjunto e interdisciplinar, a sinergia entre pares e o sentimento de unidade, há muito adormecido. Marcas que levaremos para as interações com nossos alunos, sejam elas oportunizadas pelas telas de nossos computadores ou pela já saudosa sala de aula.

\section{Referências}

ADAMS, Tony; et al. Autoethnography: understanding qualitative research. New York: Oxford University Press, UK, 2015.

ARAÚJO, José Carlos Souza. Do quadro-negro à lousa virtual: técnica, tecnologia e tecnicismo. In: VEIGA, Ilma Passos Alencastro. (org.). Técnicas de ensino: novos tempos, novas configurações (p. 13-48). Campinas, SP: Papirus, 2012.

BARDIN, Laurence. Análise de conteúdo. (L. A. Reto e A. Pinheiro trad.). São Paulo: Edições 70, 2011.

BRASIL. Atualização do parecer CNE/CP no 02/2015. Brasília: Ministério da Educação, 2019. Disponível em: < http://portal.mec.gov.br/docman/setembro-2019/124721-textoreferencia-formacao-de-professores/file>. Acesso em: 25 jun. 2021.

CARVALHO, Eliana Márcia dos Santos; ARAÚJO, Ginaldo Cardoso. Ensino remoto, saberes e formação docente: uma reflexão necessária. Revista Cocar, v. 14, n. 30, 2020.

CONTRERAS, José. A Autonomia de professores. (S. T. Valenzuela Trad.). São Paulo: Cortez, 2002.

FALSARELLA, Ana Maria. Equipe gestora e formação docente: do discurso à prática escolar. Araraquara, SP: Junqueira\&Marin, 2018.

FREITAS, André Ricardo Ribas.; NAPIMOGA, Marcelo; DONALISIO, Maria Rita. Análise da gravidade da pandemia de Covid-19. Epidemiologia e Serviços de Saúde, v. 29, n. 2, p. $1-5,2020$.

GATTI, Bernardete Angelina; BARRETTO, Elba Siqueira de Sá. Professores do Brasil: impasses e desafios. Brasília: UNESCO, 2009. 
GATTI, Bernardete Angelina; BARRETTO, Elba Siqueira de Sá; ANDRÉ, Marli Eliza Dalmazo Afonso de. Políticas docentes no Brasil: um estado da arte. Brasília: UNESCO, 2011

GATTI, Bernardete Angelina; et al. Professores do Brasil: novos cenários de formação. Brasília: UNESCO, 2019

GIMENO SACRISTÁN, José. O currículo: uma reflexão sobre a prática. 3 ed. Porto Alegre: Artmed, 2000.

HARGREAVES, Andy. Os professores em tempos de mudanças: o trabalho e a cultura dos professores na Idade Moderna. Lisboa: McGraw-Hill, 1998.

HARGREAVES, Andy.; et al. Aprendendo a mudar: o ensino para além dos conteúdos e da padronização. (R. C. Costa, Trad.). Porto Alegre: Artmed, 2002.

HUBERMAN, Michael. O ciclo de vida profissional dos professores. In: NÓVOA, António. (org.). Vidas de professores. Porto: Porto Editora, p. 31-62, 1992.

IMBERNÓN, Francisco. Formação continuada de professores. Porto Alegre: Artmed, 2010 .

IMBERNÓN, Francisco. Qualidade do ensino e formação do professorado: uma mudança necessária. São Paulo: Cortez, 2016.

KLEIMAN, Angela; MORAES, Silvia. Leitura e interdisciplinaridade. Campinas: Mercado das Letras, 2001.

MARCELO GARCÍA, Carlos. Formação de professores: para uma mudança educativa. Porto: Porto Editora, 1999.

NÓVOA, António. Formação contínua de professores: realidade e perspectivas. Portugal: Universidade de Aveiro, 1991.

NÓVOA, António. António Nóvoa: "professor se forma na escola”. [Entrevista cedida a] Paola Gentile. Nova Escola, n. 142, 2001.

NÓVOA, António (org.). Profissão Professor. Porto: Dom Quixote, 1995.

PASSALACQUA, Flávia Graziela Moreira.; et al. Necessidades formativas: um constructo para a reorganização da formação continuada de equipes escolares. Revista de Educação, Ciência e Cultura, v. 24, n. 2, p. 237-247, 2019.

REED DANAHAY, Deborah. Auto/Ethnography: Rewriting the self and the Social. New York: Berg, 1997.

SEMIS, Laís. (coord.). A situação dos professores no Brasil durante a pandemia. Nova Escola, 2020. 
Revista de Educação, Ciência e Tecnologia

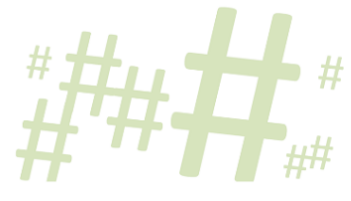

Recebido em julho de 2021.

Aprovado em outubro de 2021. 